\title{
Sex Allocation Patterns across Cooperatively Breeding Birds Do Not Support Predictions of the Repayment Hypothesis
}

\author{
Nyil Khwaja, ${ }^{1, \star}$ Ben J. Hatchwell, ${ }^{1}$ Robert P. Freckleton, ${ }^{1}$ and Jonathan P. Green ${ }^{1,2}$ \\ 1. Department of Animal and Plant Sciences, University of Sheffield, Sheffield S10 2TN, United Kingdom; 2. Department of Zoology, \\ University of Oxford, Oxford OX1 3PS, United Kingdom
}

Submitted October 24, 2016; Accepted May 16, 2017; Electronically published August 9, 2017

Online enhancements: appendix. Dryad data: http://dx.doi.org/10.5061/dryad.9bk88.

\begin{abstract}
The repayment hypothesis predicts that reproductive females in cooperative breeding systems overproduce the helping sex. Thanks to well-documented examples of this predicted sex ratio bias, repayment has been considered an important driver of variation in sex allocation patterns. Here we test this hypothesis using data on population brood sex ratios and facultative sex allocation from 28 cooperatively breeding bird species. We find that biased sex ratios of helpers do not correlate with production biases in brood sex ratios, contrary to predictions. We also test whether females facultatively produce the helping sex in response to a deficiency of help (i.e., when they have fewer or no helpers). Although this is observed in a few species, it is not a significant trend overall, with a mean effect size close to zero. We conclude that, surprisingly, repayment does not appear to be a widespread influence on sex ratios in cooperatively breeding birds. We discuss possible explanations for our results and encourage further examination of the repayment model.
\end{abstract}

Keywords: birds, cooperative breeding, local resource enhancement, repayment hypothesis, sex ratio, sex allocation.

\section{Introduction}

Fisher (1930) formulated an elegant explanation for why sex ratios are so often equal in nature. Because each offspring has a mother and father, any sex that becomes rarer immediately enjoys a reproductive success advantage, and the associated selection pressure drives population sex ratios toward parity. Exceptions to the general rule of equal sex ratios have fascinated evolutionary biologists since then (West 2009). In these cases, producing one sex confers a cost or benefit that trades off against the benefit of rarity underlying Fisher's prin-

\footnotetext{
* Corresponding author; e-mail: n.khwaja@shef.ac.uk. ORCIDs: Khwaja, http://orcid.org/0000-0003-1314-6984; Hatchwell, http:// orcid.org/0000-0002-1039-4782; Freckleton, http://orcid.org/0000-0002-8338 $-864 \mathrm{X}$.

Am. Nat. 2017. Vol. 190, pp. 000-000. (C) 2017 by The University of Chicago 0003-0147/2017/19004-57346\$15.00. All rights reserved. This work is licensed under a Creative Commons Attribution 4.0 International License (CC BY 4.0), which permits reuse of the work with attribution. DOI: $10.1086 / 693532$
}

ciple (Hamilton 1967). Sex allocation by breeders can be viewed as an adaptive decision in the context of parental investment, with the relative costs and benefits of producing each sex being key to its outcome.

In cooperative breeders, one benefit that has attracted a great deal of attention is the fitness gain that parents receive from offspring that help them in future breeding attempts (Malcolm and Marten 1982; Koenig and Walters 1999; Griffin et al. 2005). Help is usually more likely to come from one sex than the other (Komdeur 2004). The repayment hypothesis predicts that parents should invest more in this helpful sex because of the greater chance that their investment will be repaid through future help (Emlen et al. 1986; Lessells and Avery 1987). The hypothesis rests on the assumption that apparent help provides a genuine fitness benefit to breeders, and so its predictions apply only where this is the case (see "Methods").

The repayment hypothesis yields intuitive predictions about offspring sex ratios in cooperative breeders, and longterm studies of bird populations provide valuable data sets with which to test these. The first general prediction is that offspring sex ratios should be biased toward the helping sex at the population level because of the extra payoff associated with producing this sex. Brood sex ratios in bell miners ( $\mathrm{Ma}$ norina melanophrys) are consistent with this prediction: helping is extremely male biased, and $58 \%$ of hatchlings are male (Clarke et al. 2002). The second prediction is that breeders with no or fewer helpers should facultatively adjust the sex ratio of their broods to be more biased toward the helping sex, as they have more to gain from doing so. There is again some empirical support, especially from Seychelles warblers (Acrocephalus sechellensis): helping is female biased in this species, and breeders without helpers produce more females when their territory is of sufficient quality to support the extra philopatric offspring (Komdeur et al. 1997).

Despite these examples, the status of repayment as a widespread driver of sex ratio skew is called into question by a number of negative results. For example, in purple-crowned fairy wrens (Malurus coronatus) and white-banded tan- 
agers (Neothraupis fasciata) there is no significant bias toward production of the helping sex at the population level and no evidence for facultative adjustment of brood sex ratios in response to any cues (Kingma et al. 2011; Gressler et al. 2014). While the predictions of the repayment hypothesis are intuitively appealing, the adaptive value of producing each sex will also depend on difficult-to-measure components of the direct fitness of both parents and offspring. Long-term data on red-cockaded woodpeckers (Picoides borealis) have been used to estimate direct fitness differentials between the sexes and incorporate them into a repayment model; however, the model still failed to predict brood sex ratios at the population level (Koenig and Walters 1999). A meta-analysis by Griffin et al. (2005) suggests that individuals are more likely to adjust their offspring's sex ratio in systems where the benefits of help are high. This provides some explanation for failures to observe adjustment, but such negative results have proliferated since Griffin et al.'s (2005) study, perhaps because authors realize that they run counter to the prevailing view of adaptive sex allocation (Cockburn and Double 2008).

Here we use a comparative analysis and meta-analysis to test the key predictions of the repayment hypothesis, using data from previously published studies of 28 cooperatively breeding bird species spanning 18 families. We then discuss the usefulness and generality of the concept of repayment in light of our results.

\section{Methods}

We collected data from relevant studies identified using the search term "(brood) sex ratio birds" in Web of Science and Google Scholar as well as from Koenig and Dickinson (2016), Komdeur (2004), and references within. We also searched the primary literature using Web of Science for any species identified as a kin-based cooperative breeder by Riehl (2013). We included data only from bird species with kinbased cooperative breeding systems, as production is related to future help only in these cases. Where multiple studies were published for the same species, we chose the one with the largest sample size or, in the case of Seychelles warblers, the one that came from a natural population (Komdeur et al. 1997). Helper sex ratios were obtained from Green et al. (2016) or from the literature directly, where possible from the same population as brood sex ratios. Data are deposited in the Dryad Digital Repository: http://dx.doi.org/10.5061 /dryad.9bk88 (Khwaja et al. 2017).

Breeding females are expected to benefit from biasing their offspring's sex ratios toward the helping sex only if the help actually improves their fitness in turn (Emlen et al. 1986; Griffin et al. 2005). For this reason, from a data set of 32 candidate species we excluded four for which research suggests help has no positive effect on the fitness of breeding females (table A1; tables A1-A3 are available online). We included a further 10 species for which this effect has not been tested because help had a positive effect on breeder fitness in $82 \%$ of tested species $(n=22)$. We checked the influence of including these untested species by carrying out a restricted analysis in which they were removed from the data set.

We investigated the effect of helper sex ratio on logtransformed brood sex ratio across 28 species in the full data set and 18 species in the restricted data set, controlling for phylogeny using a phylogenetic generalized least squares (PGLS) model implemented in R software (ver.3.2.2). We applied this model across 1,000 trees downloaded from BirdTree .org (Jetz et al. 2012) using the Hackett et al. (2008) backbone(fig. 1). Following Green et al. (2016), we included data quality as a variance component in the model, using categories of weak, medium, or strong assigned to each study. When assigning these scores, we considered the sample size, the length of study, the sample size for the helper sex ratio estimate, and the point at which brood sex ratio was measured (with closer to the primary sex ratio being considered better quality).

For 16 studies that tested for facultative sex allocation in cooperatively breeding bird species, we used a meta-analysis to investigate the hypothesis that breeders without helpers or with fewer helpers show greater production of the helping sex. This is the strongest prediction made by the repayment hypothesis in the context of facultative allocation. We did not include studies of two species for which research suggests help has no positive effect on the fitness of breeding females, for the reasons given above. We extracted effect sizes of the relationship using equations from Lajeunesse (2013), except for two studies where we obtained effect sizes from Griffin et al. (2005). Brood sex ratio was treated as the response, and the predictor was either whether a nest was helped (categorical; seven studies) or number of helpers (integer; nine studies). We derived confidence intervals (CIs) and sample weights for each study using equations from Lipsey and Wilson (2001), and we calculated a weighted mean and 95\% CI using the Hmisc package in R (Harrell 2016).

\section{Results}

We included data on helper and brood sex ratios for 28 species of cooperatively breeding bird. The mean brood sex ratio (proportion of males) across species was $0.52 \pm 0.01 \mathrm{SE}$ (median, 0.51); this value ranged from 0.37 in broods of the black-eared miner (Manorina melanotis) to 0.69 in broods of the splendid fairy wren (Malurus splendens). The mean helper sex ratio across species was $0.80 \pm 0.05 \mathrm{SE}$ (median, 0.89 ), ranging from 0.10 in white-throated magpie jays ( $\mathrm{Ca}$ locitta formosa) to exclusively male helpers in 10 species (table A2). 

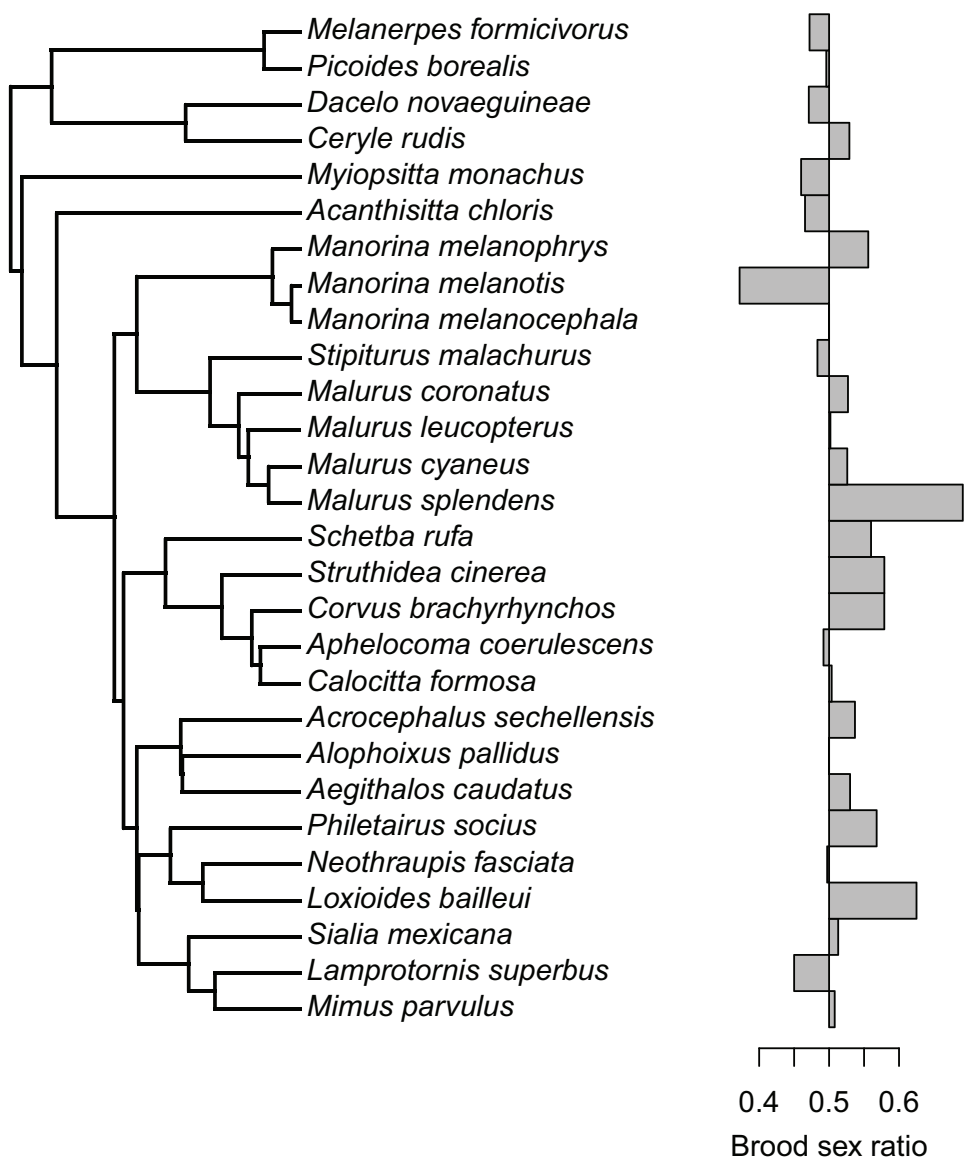

Figure 1: Phylogeny showing relationships between the 28 species used in our comparative analysis, with branch lengths from one of 1,000 sampled trees downloaded from BirdTree.org (Jetz et al. 2012). Brood sex ratio for each species is expressed as the mean proportion of males in broods from a studied population. Brood sex ratio is randomly distributed with respect to phylogeny (see "Results"). Myiopsitta monachus, Manorina melanophrys, Manorina melanotis, Manorina melanocephala, Stipiturus malachurus, Malurus leucopterus, Corvus brachyrhynchos, Alophoixus pallidus, Neothraupis fasciata, and Loxioides bailleui were excluded from a restricted analysis because of unconfirmed effects of help on breeder fitness (see "Methods").

There was effectively no phylogenetic signal to brood sex ratio (PGLS: $\lambda<0.01$; fig. 1 ). As expected, studies with a data quality score of weak accounted for more variance $\left(1.23 \lambda \times 10^{9}\right)$ than those scoring medium $\left(2.41 \lambda \times 10^{8}\right)$, and those scoring strong accounted for the least variance $\left(1.30 \lambda \times 10^{7}\right)$. Once these effects were controlled for, we found no relationship between brood sex ratio and helper sex ratio (PGLS: effect of helper sex ratio $=0.04 \pm 0.06$ SE, $R^{2}<0.01, t=0.67, P=.509$; fig. 2 ). With phylogeny accounting for such little variation, a simple linear model without phylogenetic or data quality controls produced equivalent results (ANOVA: effect of helper sex ratio $=0.02 \pm$ $\left.0.09 \mathrm{SE}, R^{2}<0.01, F_{1,26}=0.03, P=.857\right)$. Removing the 10 species for which benefits of help to breeders were unconfirmed also produced equivalent results (PGLS: effect of helper sex ratio $=0.04 \pm 0.06 \mathrm{SE}, R^{2}=0.08, t=0.67$, $P=.515)$.

We obtained effect sizes for the relationship between the number of helpers or being helped and brood sex ratios from studies of 16 cooperatively breeding bird species (fig. 3; table A3). Seven of these effects were in the expected direction, with more of the helping sex produced by unhelped females or those with fewer helpers. Seven were in the opposite direction, and the directions of two small effects were not reported. The weighted mean of the 14 effect sizes whose direction was reported was 0.01 ( $95 \% \mathrm{CI},-0.17$ to 0.036$)$ in the direction expected. This result was the same (to two decimal places) when both excluded effect sizes were treated as positive, and the weighted mean shifted to 0.00 when they were treated as negative. Effect sizes have been closer to zero 


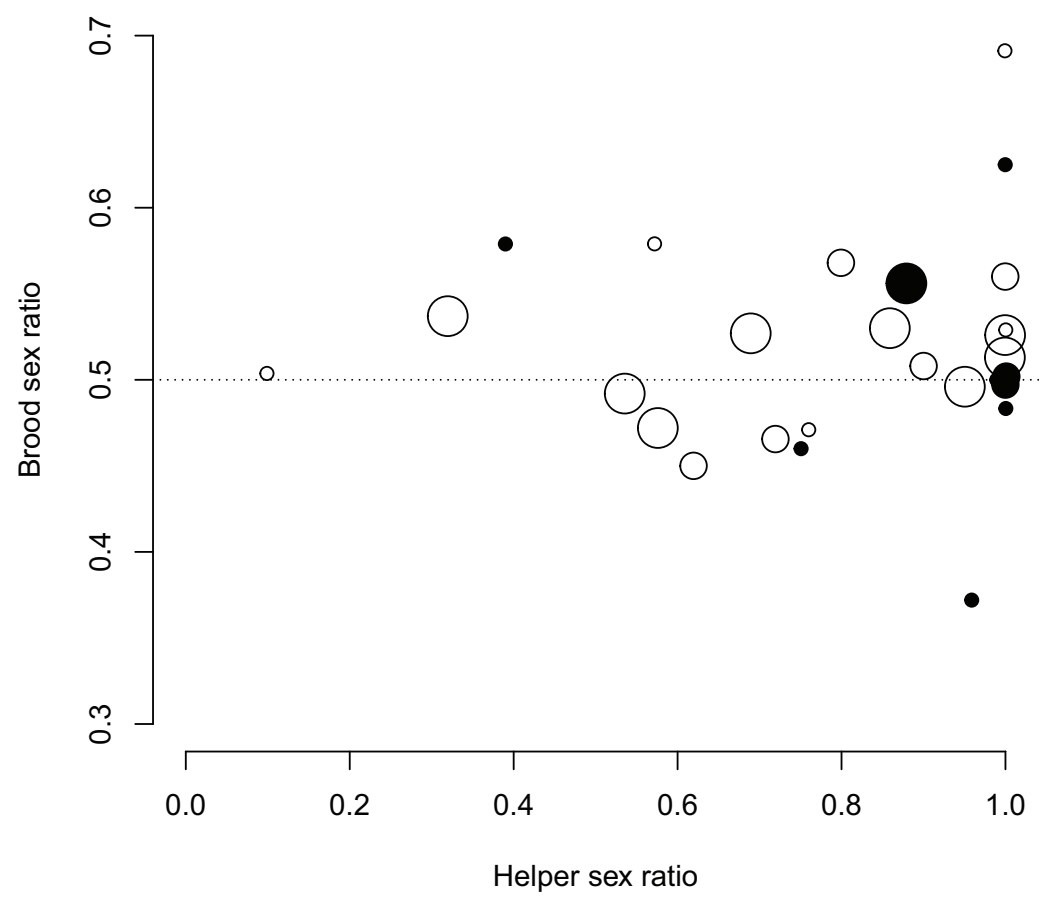

Figure 2: Observed sex ratios of helpers and broods across 28 cooperatively breeding bird species, expressed as proportions of males. There is no relationship between these two variables (see "Results"), in contrast to the predictions of the repayment hypothesis. Circle sizes represent our assessment of data quality (with large circles representing the strongest data). Filled circles correspond to species for which benefits of help to breeders are unconfirmed; these were removed from a restricted analysis (see "Methods").

in more recent studies (ANOVA: effect of year $=-0.01$, $R^{2}=0.50, F_{1,14}=14.24, P=.002$; fig. 4$)$, notably since the publication of Griffin et al.'s (2005) meta-analysis of sex ratio adjustment in cooperative breeders.

\section{Discussion}

We investigated two general predictions attributed to the repayment hypothesis. The first is that in kin-based cooperative breeders females produce broods biased toward the helpful sex because the future fitness contribution made by helpers repays some of their investment. Across 28 bird species, we found no evidence that this was generally the case, despite a lack of phylogenetic signal indicating that brood sex ratio is a labile trait. The second prediction was that females in need of help adjust their brood's sex ratios further in favour of the helping sex. We drew together tests of this prediction from 16 studies, and although it was borne out in a minority of cases, there was not a significant directional trend across species. Earlier studies reported greater effect sizes than more recent studies, which may have led to an overestimation of the prevalence of adaptive sex allocation in the literature.

\section{No Overall Bias toward Producing the More Helpful Sex}

A predicted global sex ratio skew toward the helping sex in cooperative breeders is the most direct interpretation of the repayment model; in their introduction to the original model, Emlen et al. (1986) proposed that "the sex ratio should achieve an equilibrium in which there is an overproduction of the helper sex." There are two levels at which this prediction may falter: (1) proper accounting of the costs and benefits of producing each sex and (2) empirical observation. Where sexes differ in their tendency to help, they are also likely to differ in other key life-history traits. Although one sex may "repay" investment by helping and thus improving their parents' productivity, this could feasibly be counteracted by enhanced reproductive success in the nonhelping sex improving parents' production of grandoffspring. If this is the case, biased brood sex ratios should not be adaptive. This important point was identified by Koenig and Walters (1999), who incorporated sex differences in survival and reproductive success into an extended repayment model that aimed to predict optimal brood sex ratios in red-cockaded woodpeckers. Their results were interesting in two respects: (1) the predicted optimal brood sex ratio in this species with male-biased help was still male biased and was little affected 


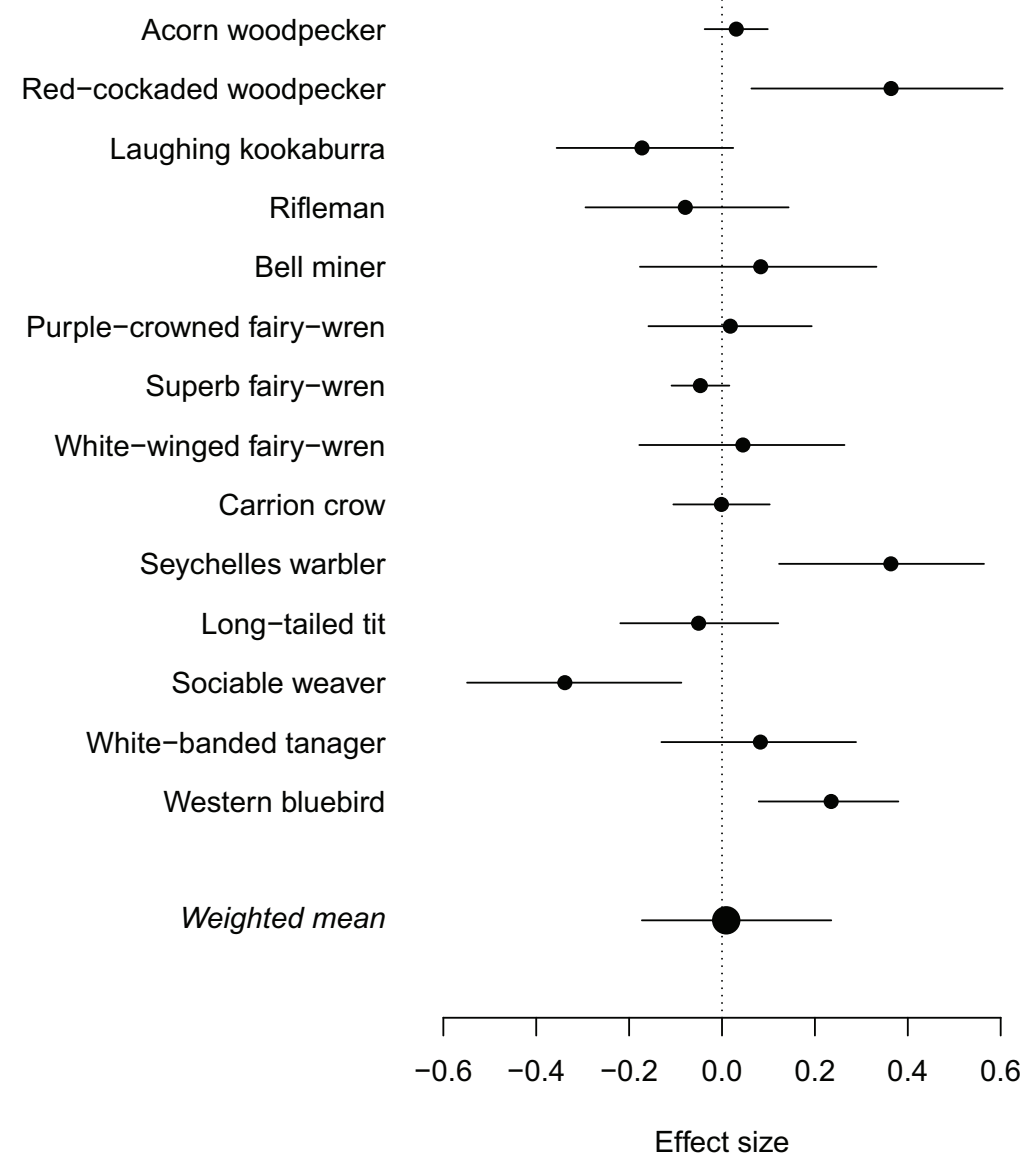

Figure 3: Effect sizes and confidence intervals from 14 studies investigating facultative production of the more helpful sex in cooperatively breeding birds. Positive effect sizes are in the direction expected from theory: females producing more of the more helpful sex when deficient of help. The effect sizes from two studies (of apostlebirds and superb starlings) are not shown because their directions were not reported (see "Results").

by considering differences in the direct fitness achieved by male and female offspring and (2) the predicted optimal brood sex ratio was significantly different from observed sex ratios, which were close to parity. Here we were unable to account for the relative influence of offspring and grandoffspring production on expected sex ratios because very few species in our sample have been studied in as much detail as the red-cockaded woodpecker. Instead, we used helper sex ratio, the key driver of expected brood sex ratio bias in Koenig and Walters (1999), and similarly found that observed brood sex ratios do not fit expectation. This does not necessarily mean that the extended repayment model as applied to red-cockaded woodpeckers also fails in other systems; it is still possible that this species is exceptional and that in most cases including sex differences in future productivity may better explain observed patterns (but see Koenig et al. 2001). For example, the benefits of rarity identified by Fisher (1930) may be much greater than the marginal fitness ben- efits associated with the likelihood of helping. Nevertheless, in general our results suggest that females biasing production toward the helping sex, which is the most intuitive prediction of repayment models, is not a valid generalization.

The repayment hypothesis makes predictions opposite to those of the local resource competition hypothesis, which suggests that females may benefit from overproducing the dispersive (generally nonhelping) sex, to reduce competition for resources (Clark 1978). Costs of competition could explain the discrepancy between our predictions and results, although there are reasons to doubt this interpretation. First, in most systems the benefits of help appear to compensate for any costs because helped nests are usually provisioned more frequently (Hatchwell 1999) and are generally more productive (Dickinson and Hatchwell 2004; Koenig and Dickinson 2016). Furthermore, if competition provided the main constraint to adaptively biasing the sex ratio, we would expect biases toward the helping sex to be especially pro- 


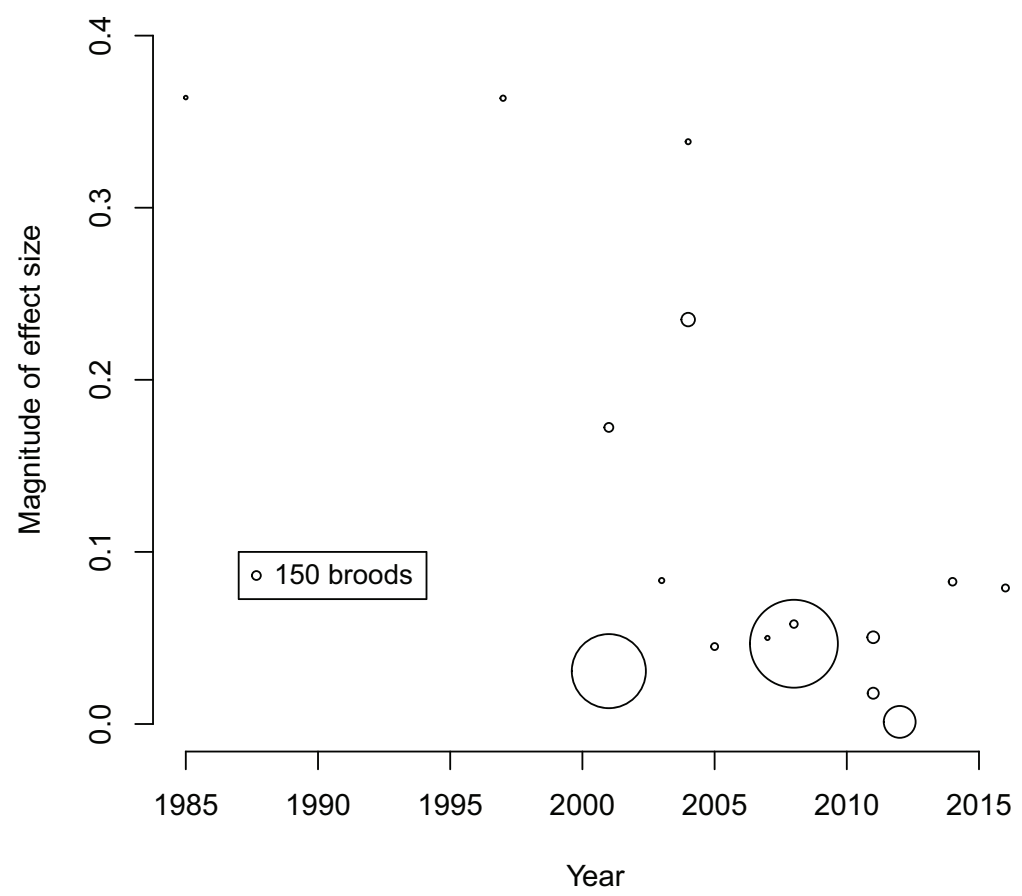

Figure 4: Relationship between the magnitude of effect sizes from studies investigating facultative sex allocation in cooperative breeders and their year of publication (see "Results"). The directions of the effects are not shown: this plot represents their distance from zero.

nounced in species like riflemen (Acanthisitta chloris), where most helpers had previously dispersed from their natal territory and the sexes do not differ significantly in their dispersal distances (Preston 2012). It is noteworthy, therefore, that the observed sex ratio is close to parity in this species (Khwaja 2017). Nevertheless, competition may limit the adaptive value of biased sex allocation in other species.

A third possible explanation is simply that biasing brood sex ratios is constrained or costly, although again this has little support. Mechanisms of biased sex allocation are currently unknown, and some suggestions rely on potentially taxon-specific characteristics, such as size dimorphism in the centromeres of sex chromosomes (Rutkowska and Badyaev 2008). However, our models showed a complete lack of phylogenetic constraint on brood sex ratios. Although across species these average around parity, some studies with convincingly large sample sizes show significantly biased population brood sex ratios (Clarke et al. 2002; Cockburn and Double 2008). There may be a mechanistic barrier to biasing sex ratios in some species, but as this is clearly not globaland phylogenetically random - it is not a well-supported interpretation (West and Sheldon 2002). While a combination of the three explanations we have suggested may underlie our results, none are especially convincing for the reasons discussed. We would welcome a theoretical reevaluation of the repayment model, which may make sense of its uneasy fit with empirical data.

\section{Rarity of Facultative Production of the More Helpful Sex}

A final candidate explanation for this lack of populationlevel brood sex ratio biases is that biases may be context dependent rather than consistent (Pen and Weissing 2000). Females may bias their broods' sex ratios only when they have fewer or no helpers (for such facultative manipulation, the local resource competition and repayment hypotheses make the same rather than opposite predictions). In contrast to the lack of evidence for population-level sex ratio biases, a few studies do provide strong support for facultative control of sex ratios. In Seychelles warblers, females show extraordinarily sophisticated control of their broods' sex ratios, with females (the more helpful sex) overproduced on good-quality territories without existing helpers (Komdeur et al. 1997, 2002). This does not, however, result in an overall population-level bias toward the production of females because males (the more dispersive sex) are overproduced on poor-quality territories, where supernumeraries are likely to be costly. Thus, in this case an unbiased population sex ratio is consistent with the repayment hypothesis because females across different contexts adaptively allocate their offspring's sex. Western 
bluebirds (Sialia mexicana) also show evidence of facultative control (Dickinson 2004), but in general our meta-analysis shows that these species are the exception rather than the rule (with an average effect size close to zero). There is no general tendency across species to produce the helping sex when breeders are deficient of help. This picture emerges strongly with the inclusion of more recent publications documenting negative results, providing a contrast to the mainly positive findings published by the time of Griffin et al.'s (2005) previous meta-analysis and leading us to somewhat different conclusions (fig. 4). We hope this encourages publication of negative results, which are essential for the validity of comparative work.

Our findings raise the question of why helpers are apparently not facultatively produced in response to "need" in other species, where there may be a plausible benefit to doing so; or, what is exceptional about Seychelles warblers? One unusual feature of this species's breeding system is that although females are more likely to become helpers than males, they are also more likely to become subordinate cobreeders that lay their own egg in the nest of the dominant pair (Richardson et al. 2001, 2002). This provides an additional selection pressure against producing philopatric females on poorquality territories, as their potential reproduction would place a further strain on resources; it is conceivable that without this additional pressure the benefits of manipulation may not outweigh its costs (see Pen et al. 1999). In addition to other species lacking such a dual selective pressure on sex ratio manipulation, we outline four suggestions below that may explain why the helping sex is elsewhere rarely overproduced in response to apparent need.

Unpredictable Environments. Adaptive sex allocation in Seychelles warblers relies on assessment of environmental quality. Philopatric females are overproduced only on territories with sufficient food (Komdeur et al. 1997). Cooperatively breeding birds are commonly associated with unpredictable environments, with extra care thought to buffer against stochasticity (Jetz and Rubenstein 2011; but see Griesser and Suzuki 2016). Species living in such conditions may lack adaptive cues for sex allocation. In acorn woodpeckers (Melanerpes formicivorus), helpers have a generally positive effect on breeders' reproductive success, but this effect becomes negative when conditions are poor (Koenig et al. 2011). A change in environmental conditions may therefore cancel any adaptive benefit of facultatively producing philopatric males.

Unpredictable Help. In species that breed in kin neighborhoods, such as riflemen and long-tailed tits (Aegithalos caudatus), helpers are not permanently affiliated with the breeding pair (Hatchwell 2009). Respectively, helpers in these species begin the breeding season dispersed onto their own territories or attempting to breed themselves, and they start help- ing at a nest partway through the provisioning phase (Preston et al. 2013; Hatchwell 2016). As a result, breeding females may not have good information on the amount of help they will receive (Nam et al. 2011). This constraint is not limited to species in kin neighborhoods: even in cooperative groups formed by delayed dispersal, it is sometimes the case that not all group members help (e.g., Rubenstein 2016), and therefore group size may be an inaccurate cue for assessing future help. Unpredictable help limits the potential for female breeders to make adaptive sex allocation decisions based on need.

Other Cues Influencing Allocation Decisions. Sociable weavers (Philetairus socius) display a surprising sex allocation pattern in which females with helpers produce relatively more rather than fewer males, the helping sex (Doutrelant et al. 2004). In this species, the need for help is clearly not a key driver of allocation decisions; the authors suggest that the inheritance of within-colony rank by philopatric males may select for overproduction of males by high-ranking breeders, which would inevitably correlate with levels of help. In whitewinged fairy wrens (Malurus leucopterus) and superb starlings (Lamprotornis superbus), sex allocation is consistent with the Trivers-Willard hypothesis, where females with better reproductive prospects overproduce males, which have higher potential fitness (Trivers and Willard 1973; Rathburn and Montgomerie 2005; Rubenstein 2007). In these species, allocation decisions based on rank and breeding condition presumably carry more benefit than those based on a need for help.

Insufficient Benefits of Help. Griffin et al. (2005) found that the benefit of help was key to the extent of facultative production of the helping sex. They used helpers' effect on productivity as a measure of this benefit. There are issues with this approach, as in some species helpers improve downstream recruitment rather than breeding productivity and in others they have less effect on productivity but provide direct benefits to breeders through load lightening (Hatchwell 1999; Hatchwell et al. 2004; Preston et al. 2016). Quantifying the total benefit that help provides to breeders is therefore challenging and potentially misleading. Nevertheless, variation in the true value of this effect is likely to explain some of the wide variation in patterns of sex ratio adjustment that we have identified in this study.

\section{Conclusion}

The repayment hypothesis is strongly supported in certain species of cooperatively breeding bird, but our study shows that its predictions do not explain variation across species. On a generalized level, we find that its importance is marginal in driving both sex ratio biases and facultative sex allocation. We 
have suggested several factors that may confound predicted results, but it is surprising that predictions from such an intuitively appealing theory do not fit observed patterns. This contrasts with the majority of work on sex allocation, in which theoretical predictions have matched empirical results with a great deal of success (West 2009). We conclude that repayment is an occasional but not widespread influence on sex allocation in cooperatively breeding birds.

\section{Acknowledgments}

This research was supported by a studentship to N.K. from the Natural Environment Research Council and the University of Sheffield. Thanks to E. Kenny and J. Jackson for help with figure production. The associate editor and two referees each made helpful comments that improved the analyses and discussion presented in this article.

\section{Literature Cited}

Clark, A. B. 1978. Sex ratio and local resource competition in a prosimian primate. Science 201:163-165.

Clarke, M. F., D. A. Jones, J. G. Ewen, R. J. Robertson, R. Griffiths, J. Painter, P. T. Boag, and R. Crozier. 2002. Male-biased sex ratios in broods of the cooperatively breeding bell miner Manorina melanophrys. Journal of Avian Biology 33:71-76.

Cockburn, A., and M. C. Double. 2008. Cooperatively breeding superb fairy-wrens show no facultative manipulation of offspring sex ratio despite plausible benefits. Behavioral Ecology and Sociobiology 62:681-688.

Dickinson, J. L. 2004. Facultative sex ratio adjustment by western bluebird mothers with stay-at-home helpers-at-the-nest. Animal Behaviour 68:373-380.

Dickinson, J. L., and B. J. Hatchwell. 2004. Fitness consequences of helping. Pages 48-66 in W. D. Koenig and J. L. Dickinson, eds. Ecology and evolution of cooperative breeding in birds. Cambridge University Press, Cambridge.

Doutrelant, C., R. Covas, A. Caizergues, and M. du Plessis. 2004. Unexpected sex ratio adjustment in a colonial cooperative bird: pairs with helpers produce more of the helping sex whereas pairs without helpers do not. Behavioral Ecology and Sociobiology 56:149-154.

Emlen, S. T., J. M. Emlen, and S. A. Levin. 1986. Sex-ratio selection in species with helpers at the nest. American Naturalist 127:1-8.

Fisher, R. A. 1930. The genetical theory of natural selection. Clarendon, Oxford.

Green, J. P., R. P. Freckleton, and B. J. Hatchwell. 2016. Variation in helper effort among cooperatively breeding bird species is consistent with Hamilton's rule. Nature Communications 7:12663.

Gressler, D. T., Z. da Paz Pereira, and M. A. Marini. 2014. Brood sex allocation in the Neotropical cooperative white-banded tanager Neothraupis fasciata. Journal of Ornithology 155:713-719.

Griesser, M., and T. N. Suzuki. 2016. Occasional cooperative breeding in birds and the robustness of comparative analyses concerning the evolution of cooperative breeding. Zoological Letters 2016:2-7.

Griffin, A. S., B. C. Sheldon, and S. A. West. 2005. Cooperative breeders adjust offspring sex ratios to produce helpful helpers. American Naturalist 166:628-632.
Hackett, S. J., R. T. Kimball, S. Reddy, R. C. K. Bowie, E. L. Braun, M. J. Braun, J. L. Chojnowski, et al. 2008. A phylogenomic study of birds reveals their evolutionary history. Science 320:1763-1768.

Hamilton, W. D. 1967. Extraordinary sex ratios. Science 156:477488.

Harrell, F. E. 2016. Hmisc: Harrell miscellaneous [R package]. https:// cran.r-project.org/web/packages/Hmisc/index.html.

Hatchwell, B. J. 1999. Investment strategies of breeders in avian cooperative breeding systems. American Naturalist 154:205-219.

- 2009. The evolution of cooperative breeding in birds: kinship, dispersal and life history. Philosophical Transactions of the Roval Societv B 364:3217-3227.

. 2016. Long-tailed tits: ecological causes and fitness consequences of redirected helping. Pages 39-57 in W. D. Koenig and J. L. Dickinson, eds. Cooperative breeding in vertebrates: studies of ecology, evolution, and behavior. Cambridge University Press, Cambridge.

Hatchwell, B. J., A. F. Russell, A. D. C. MacColl, D. J. Ross, M. K. Fowlie, and A. McGowan. 2004. Helpers increase long-term but not shortterm productivity in cooperatively breeding long-tailed tits. Behavioral Ecology 15:1-10.

Jetz, W., and D. R. Rubenstein. 2011. Environmental uncertainty and the global biogeography of cooperative breeding in birds. Current Biology 21:72-78.

Jetz, W., G. H. Thomas, J. B. Joy, K. Hartmann, and A. O. Mooers. 2012. The global diversity of birds in space and time. Nature 491: $444-448$.

Khwaja, N. 2017. Investment patterns and kinship cues in a cooperatively breeding bird. $\mathrm{PhD}$ thesis, University of Sheffield.

Khwaja, N., B. J. Hatchwell, R. P. Freckleton, and J. P. Green. 2017 Data from: Sex allocation patterns across cooperatively breeding birds do not support predictions of the repayment hypothesis. American Naturalist, Dryad Digital Repository, http://dx.doi.org/10.5061 /dryad.9bk88.

Kingma, S. A., M. L. Hall, and A. Peters. 2011. No evidence for offspring sex-ratio adjustment to social or environmental conditions in cooperatively breeding purple-crowned fairy-wrens. Behavioral Ecology and Sociobiology 65:1203-1213.

Koenig, W. D., and J. L. Dickinson, eds. 2016. Cooperative breeding in vertebrates: studies of ecology, evolution, and behavior. Cambridge University Press, Cambridge.

Koenig, W. D., M. T. Stanback, J. Haydock, and F. Kraaijeveld-Smit. 2001. Nestling sex ratio variation in the cooperatively breeding acorn woodpecker (Melanerpes formicivorus). Behavioral Ecology and Sociobiology 49:357-365.

Koenig, W. D., and J. R. Walters. 1999. Sex-ratio selection in species with helpers at the nest: the repayment model revisited. American Naturalist 153:124-130.

Koenig, W. D., E. L. Walters, and J. Haydock. 2011. Variable helper effects, ecological conditions, and the evolution of cooperative breeding in the acorn woodpecker. American Naturalist 178:145-158.

Komdeur, J. 2004. Sex-ratio manipulation. Pages 102-116 in W. D. Koenig and J. L. Dickinson, eds. Ecology and evolution of cooperative breeding in birds. Cambridge University Press, Cambridge.

Komdeur, J., S. Daan, J. Tinbergen, and A. C. Mateman. 1997. Extreme adaptive modification in sex ratio of the Seychelles warbler's eggs. Nature 385:522-585.

Komdeur, J., M. J. L. Magrath, and S. Krackow. 2002. Pre-ovulation control of hatchling sex ratio in the Seychelles warbler. Proceedings of the Roval Society B 269:1067-1072. 
Lajeunesse, M. J. 2013. Recovering missing or partial data from studies: a survey of conversions and imputations for meta-analysis. Pages 195-206 in J. Koricheva, J. Gurevitch, and K. Mengersen, eds. Handbook of meta-analysis in ecology and evolution. Princeton University Press, Princeton, NJ.

Lessells, C. M., and M. I. Avery. 1987. Sex-ratio selection in species with helpers at the nest: some extensions of the repayment model. American Naturalist 129:610-620.

Lipsey, M. W., and D. B. Wilson. 2001. Practical meta-analysis. Sage, New York.

Malcolm, J. R., and K. Marten. 1982. Natural selection and the communal rearing of pups in African wild dogs (Lycaon pictus). Behavioral Ecology and Sociobiology 10:1-13.

Nam, K.-B., J. Meade, and B. J. Hatchwell. 2011. Brood sex ratio variation in a cooperatively breeding bird. Iournal of Evolutionary Biology 24:904-913.

Pen, I., and F. J. Weissing. 2000. Sex-ratio optimization with helpers at the nest. Proceedings of the Roval Societv B 267:539-543.

Pen, I., F. J. Weissing, and S. Daan. 1999. Seasonal sex ratio trend in the European kestrel: an evolutionarily stable strategy analysis. American Naturalist 153:384-397.

Preston, S. A. J. 2012. Routes to cooperation in the rifleman, Acanthisitta chloris. $\mathrm{PhD}$ thesis, University of Sheffield.

Preston, S. A. J., J. V. Briskie, T. Burke, and B. J. Hatchwell. 2013. Genetic analysis reveals diverse kin-directed routes to helping in the rifleman Acanthisitta chloris. Molecular Ecology 22:5027-5039.

Preston, S. A. J., J. V. Briskie, and B. J. Hatchwell. 2016. Adult helpers increase the recruitment of closely related offspring in the cooperatively breeding rifleman. Behavioral Ecology 27:16171626.

Rathburn, M. K., and R. Montgomerie. 2005. Offspring sex ratios correlate with pair-male condition in a cooperatively breeding fairywren. Behavioral Ecology 16:41-47.

Richardson, D., F. Jury, K. Blaakmeer, J. Komdeur, and T. Burke. 2001. Parentage assignment and extra-group paternity in a cooperative breeder: the Seychelles warbler (Acrocephalus sechellensis). Molecular Ecology 10:2263-2273.

Richardson, D., J. Komdeur, and T. Burke. 2002. Direct benefits and the evolution of female-biased cooperative breeding in Seychelles warblers. Evolution 56:2313-2321.

Riehl, C. 2013. Evolutionary routes to non-kin cooperative breeding in birds. Proceedings of the Roval Societv B 280:20132245.

Rubenstein, D. R. 2007. Temporal but not spatial environmental variation drives adaptive offspring sex allocation in a plural cooperative breeder. American Naturalist 170:155-165.

- 2016. Superb starlings: cooperation and conflict in an unpredictable environment. Pages 181-196 in W. D. Koenig and J. L. Dickinson, eds. Cooperative breeding in vertebrates: studies of ecology, evolution, and behavior. Cambridge University Press, Cambridge.

Rutkowska, J., and A. V. Badyaev. 2008. Meiotic drive and sex determination: molecular and cytological mechanisms of sex ratio adjustment in birds. Philosophical Transactions of the Roval Societv B $363: 1675-1686$.

Trivers, R. L., and D. E. Willard. 1973. Natural selection of parental ability to vary the sex ratio of offspring. Science 179:90-92.

West, S. A. 2009. Sex allocation. Princeton University Press, Princeton, NJ.

West, S. A., and B. C. Sheldon. 2002. Constraints in the evolution of sex ratio adjustment. Science 295:1685-1688.

\section{References Cited Only in the Online Appendixes}

Arnold, K. E., S. C. Griffith, and A. W. Goldizen. 2001. Sex-biased hatching sequences in the cooperatively breeding noisy miner. Journal of Avian Biology 32:219-223.

Asai, S., S. Yamagishi, and K. Eguchi. 2003. Mortality of fledgling females causes male bias in the sex ratio of rufous vangas (Schetba rufa) in Madagascar. Auk 120:700-705.

Bednarz, J. C. 1987. Pair and group reproductive success, polyandry, and cooperative breeding in Harris' hawks. Auk 104:393-404.

Berg, E. C. 2004. A test of sex-ratio biasing in the white-throated magpie-jay, a cooperative breeder with female helpers. Condor 106: 299-308.

Bucher, E. H., J. J. Martínez, and M. C. de Aranzamendi. 2016. Genetic relatedness in monk parakeet breeding trios. Lournal of Ornithology 157:1119-1122.

Caffrey, C. 1992. Female-biased delayed dispersal and helping in American crows. Auk 109:609-619.

Canestrari, D., M. Vila, J. M. Marcos, and V. Baglione. 2012. Cooperatively breeding carrion crows adjust offspring sex ratio according to group composition. Behavioral Ecology and Sociobiology 66: $1225-1235$.

Cockburn, A., L. Brouwer, N. Margraf, H. L. Osmond, and M. van de Pol 2016. Superb fairy-wrens: making the worst of a good job. Pages 133-149 in W. D. Koenig and J. L. Dickinson, eds. Cooperative breeding in vertebrates: studies of ecology, evolution, and behavior. Cambridge University Press, Cambridge.

Covas, R., A. Dalecky, A. Caizergues, and C. Doutrelant. 2006. Kin associations and direct vs indirect fitness benefits in colonial cooperatively breeding sociable weavers Philetairus socius. Behavioral Ecology and Sociobiology 60:323-331.

Covas, R., M. du Plessis, and C. Doutrelant. 2008. Helpers in colonial cooperatively breeding sociable weavers Philetairus socius contribute to buffer the effects of adverse breeding conditions. Behavioral Ecology and Sociobiology 63:103-112.

Curry, R. L. 1988. Influence of kinship on helping behavior in Galápagos mockingbirds. Behavioral Ecology and Sociobiology 22:141-152.

Curry, R. L., and P. R. Grant. 1989. Demography of the cooperatively breeding Galapagos mockingbird, Nesomimus parvulus, in a climatically variable environment. Journal of Animal Ecology 58:441-463.

Dickinson, J. L., C. Akçay, E. D. Ferree, and C. A. Stern. 2016. Western bluebirds: lessons from a marginal cooperative breeder. Pages 1938 in W. D. Koenig and J. L. Dickinson, eds. Cooperative breeding in vertebrates: studies of ecology, evolution, and behavior. Cambridge University Press, Cambridge.

Dickinson, J. L., W. D. Koenig, and F. A. Pitelka. 1996. Fitness consequences of helping behavior in the western bluebird. Behavioral Ecology 7:168-177.

Du, B., and X. Lu. 2009. Bi-parental vs. cooperative breeding in a passerine: fitness-maximizing strategies of males in response to risk of extra-pair paternity? Molecular Ecology 18:3929-3939.

du Plessis, M. 1993. Helping behaviour in cooperatively-breeding green woodhoopoes: selected or unselected trait? Behaviour 127:49-65.

Eberhard, J. R. 1998. Breeding biology of the monk parakeet. Wilson Bulletin 110:463-473.

Eguchi, K., S. Asai, and S. Yamagishi. 2009. Individual differences in the helping behaviors of cooperatively breeding rufous vangas. Ornithological Science 8:5-13.

Ewen, J. G., R. H. Clarke, E. Moysey, R. L. Boulton, R. H. Crozier, and M. F. Clarke. 2001. Primary sex ratio bias in an endangered coop- 
eratively breeding bird, the black-eared miner, and its implications for conservation. Biological Conservation 101:137-145.

Ewen, J. G., R. H. Crozier, P. Cassey, T. Ward-Smith, J. N. Painter, R. J. Robertson, D. A. Jones, and M. F. Clarke. 2003. Facultative control of offspring sex in the cooperatively breeding bell miner, Manorina melanophrys. Behavioral Ecology 14:157-164.

Fitzpatrick, J. W., and R. Bowman. 2016. Florida scrub-jays: oversized territories and group defense in a fire-maintained habitat. Pages 77-96 in W. D. Koenig and J. L. Dickinson, eds. Cooperative breeding in vertebrates: studies of ecology, evolution, and behavior. Cambridge University Press, Cambridge.

Gowaty, P. A., and M. R. Lennartz. 1985. Sex ratios of nestling and fledgling red-cockaded woodpeckers (Picoides borealis) favor males. American Naturalist 126:347-353.

Innes, K. E., and R. E. Johnston. 1996. Cooperative breeding in the white-throated magpie-jay: how do auxiliaries influence nesting success? Animal Behaviour 51:519-533.

Kingma, S. A., M. L. Hall, E. Arriero, and A. Peters. 2010. Multiple benefits of cooperative breeding in purple-crowned fairy-wrens: a consequence of fidelity? Journal of Animal Ecology 79:757-768.

Kingma, S. A., M. L. Hall, G. Segelbacher, and A. Peters. 2009. Radical loss of an extreme extra-pair mating system. BMC Ecology 9:15.

Kinnaird, M. F., and P. R. Grant. 1981. Cooperative breeding by the Galápagos mockingbird, Nesomimus parvulus. Behavioral Ecology and Sociobiology 10:65-73.

Koenig, W. D., and J. L. Dickinson. 1996. Nestling sex-ratio variation in western bluebirds. Auk 108:79-88.

Koenig, W. D., E. L. Walters, and J. Haydock. 2016. Acorn woodpeckers: helping at the nest, polygynandry, and dependence on a variable acorn crop. Pages 217-236 in W. D. Koenig and J. L. Dickinson, eds. Cooperative breeding in vertebrates: studies of ecology, evolution, and behavior. Cambridge University Press, Cambridge.

Komdeur, J., T. Burke, H. Dugdale, and D. S. Richardson. 2016. Seychelles warblers: complexities of the helping paradox. Pages 197216 in W. D. Koenig and J. L. Dickinson, eds. Cooperative breeding in vertebrates: studies of ecology, evolution, and behavior. Cambridge University Press, Cambridge.

Legge, S. 2000. Helper contributions in the cooperatively breeding laughing kookaburra: feeding young is no laughing matter. Animal Behaviour 59:1009-1018.

Legge, S., and A. Cockburn. 2000. Social and mating system of cooperatively breeding laughing kookaburras (Dacelo novaeguineae). Behavioral Ecology and Sociobiology 47:220-229.

Legge, S., R. G. Heinsohn, M. C. Double, R. Griffiths, and A. Cockburn. 2001. Complex sex allocation in the laughing kookaburra. Behavioral Ecology 12:524-533.

Lennartz, M. R., R. G. Hooper, and R. F. Harlow. 1987. Sociality and cooperative breeding of red-cockaded woodpeckers, Picoides borealis. Behavioral Ecology and Sociobiology 20:77-88.

Lindsey, G. D., S. G. Fancy, M. H. Reynolds, T. K. Pratt, K. A. Wilson, and J. D. Jacobi. 1995. Population structure and survival of palila. Condor 97:528-535.

Maguire, G. S., and R. A. Mulder. 2004. Breeding biology and demography of the southern emu-wren (Stipiturus malachurus). Australian Iournal of Zoology 52:583-604.
Manica, M. T., and M. A. Marini. 2011. Helpers at the nest of whitebanded tanager Neothraupis fasciata benefit male breeders but do not increase reproductive success. Journal of Ornithology 153:149159.

Mulder, R. A. 1994. Natal and breeding dispersal in a co-operative, extra-group-mating bird. Journal of Avian Biology 26:234-240.

Patch-Highfill, L. D. 2008. Estimating genetic diversity of palila (Loxioides bailleui) and familial relationships of helper males. MS thesis, University of Hawai i, Honolulu.

Reyer, H.-U. 1990. Pied kingfishers: ecological causes and reproductive consequences of cooperative breeding. Pages 527-557 in P. B. Stacey and W. D. Koenig, eds. Cooperative breeding in birds: longterm studies of ecology and behavior. Cambridge University Press, Cambridge.

Russell, E., and I. Rowley. 1988. Helper contributions to reproductive success in the splendid fairy-wren (Malurus splendens). Behavioral Ecology and Sociobiology 22:131-140.

Sankamethawee, W., B. D. Hardesty, and G. A. Gale. 2010. Sex-bias and timing of natal dispersal in cooperatively breeding puff-throated bulbuls Alophoixus pallidus. Journal of Ornithology 151:779-789.

Varian-Ramos, C. W., J. Karubian, V. Talbott, I. Tapia, and M. S. Webster. 2010. Offspring sex ratios reflect lack of repayment by auxiliary males in a cooperatively breeding passerine. Behavioral Ecology and Sociobiology 64:967-977.

Walters, J. R., and V. Garcia. 2016. Red-cockaded woodpeckers: alternative pathways to breeding success. Pages 58-76 in W. D. Koenig and J. L. Dickinson, eds. Cooperative breeding in vertebrates: studies of ecology, evolution, and behavior. Cambridge University Press, Cambridge.

Webster, M. S., K. A. Tarvin, E. M. Tuttle, and S. Pruett-Jones. 2004 Reproductive promiscuity in the splendid fairy-wren: effects of group size and auxiliary reproduction. Behavioral Ecology 15:907915.

Woolfenden, G. E., and J. W. Fitzpatrick. 1984. The Florida scrub jay: demography of a cooperative-breeding bird. Princeton University Press, Princeton, NJ.

Woxvold, I. A, and M. J. L. Magrath. 2005. Helping enhances multiple components of reproductive success in the cooperatively breeding apostlebird. Journal of Animal Ecology 74:1039-1050.

2008. Sex-biases in the hatching sequence of cooperatively breeding apostlebirds Struthidea cinerea. Evolutionarv Ecology 22: 139-151.

Woxvold, I. A., R. A. Mulder, and M. J. L. Magrath. 2006. Contributions to care vary with age, sex, breeding status and group size in the cooperatively breeding apostlebird. Animal Behaviour 72:6373 .

Wright, J., P. G. McDonald, L. te Marvelde, A. J. N. Kazem, and C. M. Bishop. 2010. Helping effort increases with relatedness in bell miners, but "unrelated" helpers of both sexes still provide substantial care. Proceedings of the Roval Societv B 277:437-445.

Associate Editor: Christina Riehl Editor: Yannis Michalakis 